\title{
Enhancing Learning and Engagement through Embodied Interaction within a Mixed Reality Simulation
}

\begin{abstract}
Computer simulations have been shown to be effective instruments for teaching students about difficult concepts, particularly in the STEM disciplines. Emerging interface technologies are expanding the modalities with which learners can interact with these simulations, but the effects of these new interactions on conceptual understanding and student engagement have not been examined in great depth. We present here a study where middle school students learned about gravity and planetary motion in an immersive, whole-body interactive simulation, and we compared their learning and attitudes about science with students who used a desktop version of the same simulation. Results of the study indicate that enacting concepts and experiencing critical ideas in physics through whole-body activity leads to significant learning gains, higher levels of engagement, and more positive attitudes towards science.
\end{abstract}

\section{Keywords}

Interactive learning environments; mixed reality; embodied learning; science education

\section{Introduction}

Previous research has demonstrated that interactive computer simulations have properties that can effectively facilitate learning and engagement in science (D'Angelo, Rutstein, Harris, Bernard, Borokhovski, \& Haertel, 2014; National Research Council, 2011; Rutten, van Joolingen, \& van der Veen, 2012; Smetana \& Bell, 2012). This research has primarily focused 
on desktop or laptop-based computer simulations that are operated with mouse and keyboard controls. There is an emerging literature, however, describing learning benefits of more expressive and embodied interactions with science content (e.g., Plummer, 2009; Richards, 2012) and new technologies with tangible and gesture-controlled interfaces have started to show enhanced learning effects (e.g., Chiu, DeJaegher, \& Chao, 2015; Han \& Black, 2011; Enyedy, Danish, Delacruz \& Kumar, 2010; Johnson-Glenberg, Birchfield, Tolentino \& Koziupa, 2014). This includes environments where the body is cued to enact certain actions and create physical representations that facilitate conceptual understanding (Author, 2015). The design rationale is that having learners act out and physicalize the systems, processes, relationships, etc., that they are trying to understand-as opposed to externally manipulating these systems and processes (e.g., with a computer mouse)—will create conceptual anchors from which new knowledge can be built. Up to this point, there has been little research examining outcomes for students learning the same science content in the same simulation environment, differing only in the degree of immersion and physical interaction with the interface.

This study investigates the effects of a whole-body, mixed reality simulation game on science learning outcomes by comparing participant performance in the experimental simulation to a control group using the same simulation game on a desktop computer. To conduct this study, we designed and developed a room-sized simulation called MEteor that integrates floor- and wall-projections with a laser-based motion tracking system to embed learners in a realistic representation of planetary astronomy. Students using the simulation are prompted to make predictions about the trajectory of an asteroid as it comes into the vicinity of gravitational forces (e.g., nearby planets). Real-time feedback about the accuracy of these predictions cues students to make adjustments and move in a way that is consistent with normative ideas in physics. Our 
hypothesis is that giving students the opportunity to enact these ideas with their bodies, and connect them to representational supports (graphs and other visualizations), will build student intuitions and facilitate subsequent reasoning about physical systems. We further hypothesize that this embodied engagement will heighten feelings of agency and efficacy, leading to more positive attitudes about science and perceived value of the simulation experience. This paper describes findings from several measures of learning and learner engagement administered to middle school student participants, and we discuss implications of these results for the design of interactive learning environments and research on embodied learning.

\subsection{Learning Science with Interactive Computer Simulations}

In their review of the literature, Rutten, van Joolingen, \& van der Veen (2012) found robust support for simulations in enhancing science instruction, complementing laboratory activities, and promoting learner discovery of important science concepts. A recent National Research Council additionally highlights the potential of simulations to "advance multiple science learning goals, including motivation to learn science, conceptual understanding, science

process skills, understanding of the nature of science, scientific discourse and argumentation, and identification with science and science learning” (NRC, 2011,pg. 2). Beyond numerous practical benefits (cost, safety), science education simulations have the ability to show otherwise unobservable processes such as plate tectonics or molecular biology. Simulations have also been shown to have cognitive affordances for conceptual development and understanding such as supporting personal experimentation and providing opportunities for making connections to existing knowledge (e.g., de Jong \& van Joolingen, 1998; Richards, Barowy, \& Levin, 1992; Swaak \& de Jong, 2001; Windschitl \& Andre, 1998; Winn, Stahr, Sarason, Fruland, Oppenheimer, \& Lee, 2006). 
Most simulation and learning research to date has focused on simulation interactions employing typical computer interface controls such as the mouse and keyboard; however, there are additional affordances of simulations for learning that can potentially be leveraged by expanding the interaction space to more physical and embodied modalities. For example, computer simulations have unique spatial properties that allow for sophisticated knowledge representations (e.g., Dalgarno \& Lee, 2010; Falloon, 2010; Luo, Luo, Wickens, \& Chen, 2010; Monaghan \& Clement, 1999; van der Meij \& de Jong, 2006) and which allow students to leverage natural and powerful perceptual capacities such as visual differentiation and perceptionaction tuning (Author, 2009). Simulations are also effective at eliciting learner actions and prompting them to make choices that can expose and directly confront students with their misconceptions, while also presenting opportunities for remediation (Author, 2014; Stieff \& Wilensky, 2003). Finally, simulations can contextualize scientific processes and practices, and even immerse learners in such a way that they adopt novel perspectives and develop important intuitions that cultivate more expert-like thinking (Barnett, 2005; Clark \& Jorde, 2004; Dede, 2009; Gelbart, Brill, \& Yarden, 2009). While these benefits exist for traditional computer simulations, the potential to engage spatial reasoning and action-based choices while immersing students in science knowledge and phenomena is amplified by new technologies that permit more physical and expressive body input.

It is also possible that new forms of interaction can mitigate some of the limitations of simulation-based learning. For example, in an effort to make simulations accurate and consistent with formal ideas in science, there is a tendency to present learning content using highly abstracted representations. Simulations that connect concepts to physical activity such as make the content more concrete or "grounded" (e.g., Vitale, Swart, \& Black, 2014). Another limitation 
of simulations is the challenge of finding effective ways to administer feedback on user interactions. Traditional computer simulations will frequently fall back on verbal feedback protocols (e.g., "You may have noticed..." or "Why don't you try...") that are reminiscent of formal instruction and may be detrimental to learner agency. Embodied interaction with simulations opens up new modalities for feedback that directly connect to the senses and perceptions of the learner such as the use of haptic feedback for learning about force and kinematics (Han \& Black, 2011).

\subsection{Embodied learning}

Outside of its affordances for implementation in computer simulations, there is a strong rationale and an emerging literature that supports engaging the body in learning activities. Proponents of embodied cognition argue that how people think and reason about the world is deeply connected to our sensorimotor system and the body's interaction with the physical environment (e.g., Barsalou, 2008; Glenberg, 2010; Johnson, 1987). It follows that body movement can also impact our processes of learning, and empirical studies have shown that having students move in prescribed ways can benefit learning and performance in areas such as algebra (Goldin-Meadow, Cook, \& Mitchell, 2009). It is clearly not the case, however, that any body movement will engender learning, and recent studies of embodied learning have focused on the notion of congruency (Johnson-Glenberg et al., 2014; Segal, 2011) — a condition under which movements or body positioning map coherently onto a particular conceptual domain. Designing learning environments that effectively create the conditions for embodied learning is becoming an emerging area of research and design (e.g., Abrahamson, 2014; Author, 2013, Author, 2014; Black, Segal, Vitale, \& Fadjo, 2011). 
While much of the research on embodiment and learning has been conducted in the area of mathematics (e.g., Nemirovsky \& Ferrara, 2009), there is also a strong foundation for applications of embodied cognition to the learning of science. A basic tenet of embodied cognition is that notions of space, motion, force, etc., arise because of sensorimotor interactions with one's environment (Inhelder \& Piaget, 1958; Gallese \& Lakoff, 2005; Wilson, 2002). For example, moving oneself and making other objects move leads to the development of ideas about motion. Many in science education have argued that formal instruction should be built from these embodied experiences with the world (e.g., Cheng \& Brown, 2010; Niebert, Marsch, \& Treagust, 2012). Some have further argued that science education should seed learning activities by having students move in expressive ways (i.e., whole-body, unconstrained motion), and a few studies across the range of K-16 education in a variety of science topics have shown benefits for prompting students' motion as a means of instigating new learning (Plummer, 2009; Richards, 2012; Solomon, Bevan, Frost, Reynolds, Summers, \& Zimmerman, 1991).

\subsection{Facilitating Embodied Learning with Digital Environments}

We are in the midst of an aggressive expansion of interface capabilities with digital technologies that increasingly allows users to interact with computers in more natural and physically expressive ways (c.f., Jacob, Audrey, Hirshfield, Horn, Shaer, Solovey, \& Zigelbaum, 2008). These technologies include phones and tablet computers that permit mobility and augmented camera views, as well as tangible interfaces and more immersive environments that combine virtual and physical elements - what has been referred to as "mixed reality" (Milgram \& Kishino, 1994). Educational researchers have taken notice of these expanded repertoires of interaction and have described affordances for learning and understanding (Author, 2013; Bujak, Radu, Catrambone, MacIntyre, Zheng, \& Golubski, 2013; Chang, Lee, Wang, \& Chen, 2010; 
Wu, Lee, Chang, \& Liang, 2013). Resnick (2006), for example, describes how digital technologies can guide students to perform physical actions that serve as "conceptual leverage."

Recent research has begun to demonstrate learning effects of embodied interactions with emerging technologies, particularly in STEM content areas. For example, a recent study on students using their bodies to learn about centripetal force using a computer simulation showed that participants in the "high embodiment" condition (swinging a trackable object over their heads) showed higher long-term learning gains in physics compared to students in a "low embodiment" condition (initializing a simulation using a mouse) (Johnson-Glenberg et al., 2014). Another study embedded elementary school students in simulations of force and motion that allowed them to successfully connect their physical activity with formal representations of these phenomena, a process the authors refer to as "progressive symbolization" (Enyedy et al., 2012). While there have been exciting developments in this space, it is important to note that embodied interaction design strategies and the learning measures used to study them have varied significantly. In this study we look at an environment that embeds learners within a science simulation and prompts them to physically enact their emerging understanding of physics concepts.

\subsection{Embodied Interaction and Increased Learner Engagement and Positive Attitudes}

In addition to outcomes pertaining to learner understanding and conceptual development, research has also shown promising dispositional effects of embodied interaction with learning content. Empirical studies of students engaged in kinesthetically-enhanced learning activities with digital technologies in a variety of contexts have shown benefits in terms of increased student engagement (Anastopoulou, Sharples, \& Baber, 2011; Dunleavy, Dede, \& Mitchell, 2009; Jones, Minogue, Tretter, Negishi, \& Taylor, 2006). Measures of engagement in these 
studies include student responses to questionnaires probing perceptions and attitudes towards instruction as well as observations of participants' activity and behavior. Researchers have put forth a number of different rationales why embodied interaction may lead to increased learner motivation. For example, the notion that physical exploration of one's environment can give rise to student attitudes that drive new learning is a fundamental tenet of constructionist learning theories that argue for increased learner agency around material objects that can be manipulated and explored (Kafai, 2006; Papert, 1980). Others have argued that body-based experiences are more perceptually immersive and lead to greater feelings of "presence" such that learners may feel that they are in a more authentic and meaningful educational space (Dede, 2009; De Freitas, Rebolledo-Mendez, Liarokapis, Magoulas, \& Poulovassilis, 2010; Winn, 2003). A further characteristic of embodied interfaces is the opportunity to adopt a particular visual or haptic perspective. Studies have shown that technology-guided attention can induce more expert-like thinking and problem solving (Author, 2012; Grant \& Spivey, 2003), and it may be that these experiences also engender more expert-like attitudes and dispositions, such as confidence in one's ability to address problems in the domain or an identification with a content area such as science.

\subsection{The MEteor Project: Learning through Enacted Predictions of How Objects Move in}

\section{Space}

MEteor is an interactive simulation of planetary astronomy that is projected onto a large (30x10 foot) floor surface. The simulation presents an accurate representation of gravitational forces that affect astronomical objects such as asteroids. The MEteor floor simulation is accompanied by an adjacent wall projection that offers basic instructions and presents data on a learner's performance within the simulation that can be reviewed and used to inform subsequent 
activity. Laser scanning technology allows MEteor to precisely track a learner's position within the simulation and enables the learner to play the role of an asteroid moving within the simulation space. The intent is to embed participants in the phenomenon they are trying to understand, in the spirit of what Colella (2000) calls "participatory simulations."

The primary objective of MEteor users is to use their bodies to make accurate predictions of how the asteroid will move when it encounters forces such as the gravitational fields of nearby planets (Figure 1). Users enact their predictions in two phases. First, they move their bodies to place an asteroid into a "virtual spring launcher" (Figure 2) and set the initial launch parameters (position, speed, and angle) that they believe will accomplish the goal of each level (e.g., hitting a target located at the end of the simulation platform). Second, they initiate their launch by stepping forward in the spring launcher and moving through the simulation in the path they expect the asteroid will travel. The learner is given feedback on their performance in real time by showing the actual path the asteroid would take if governed by the laws of physics. If the learner's path diverges from the normative path the learner can quickly adjust - speeding up to catch an asteroid that is moving faster than anticipated, for example. This real time feedback is meant to cue the learner to the features of an asteroid's movement when it encounters a planet (e.g., gravitational acceleration), however, the learner does not succeed in the simulation until they are able to predict this movement in advance and move naturally with the correct trajectory. The learner also receives after-action feedback in the form of graphical representations projected on the wall display (Figure 3). This display shows the learner their path compared to the correct path, allowing the learner to reflect on their strategy and make adjustments for their next launch. 


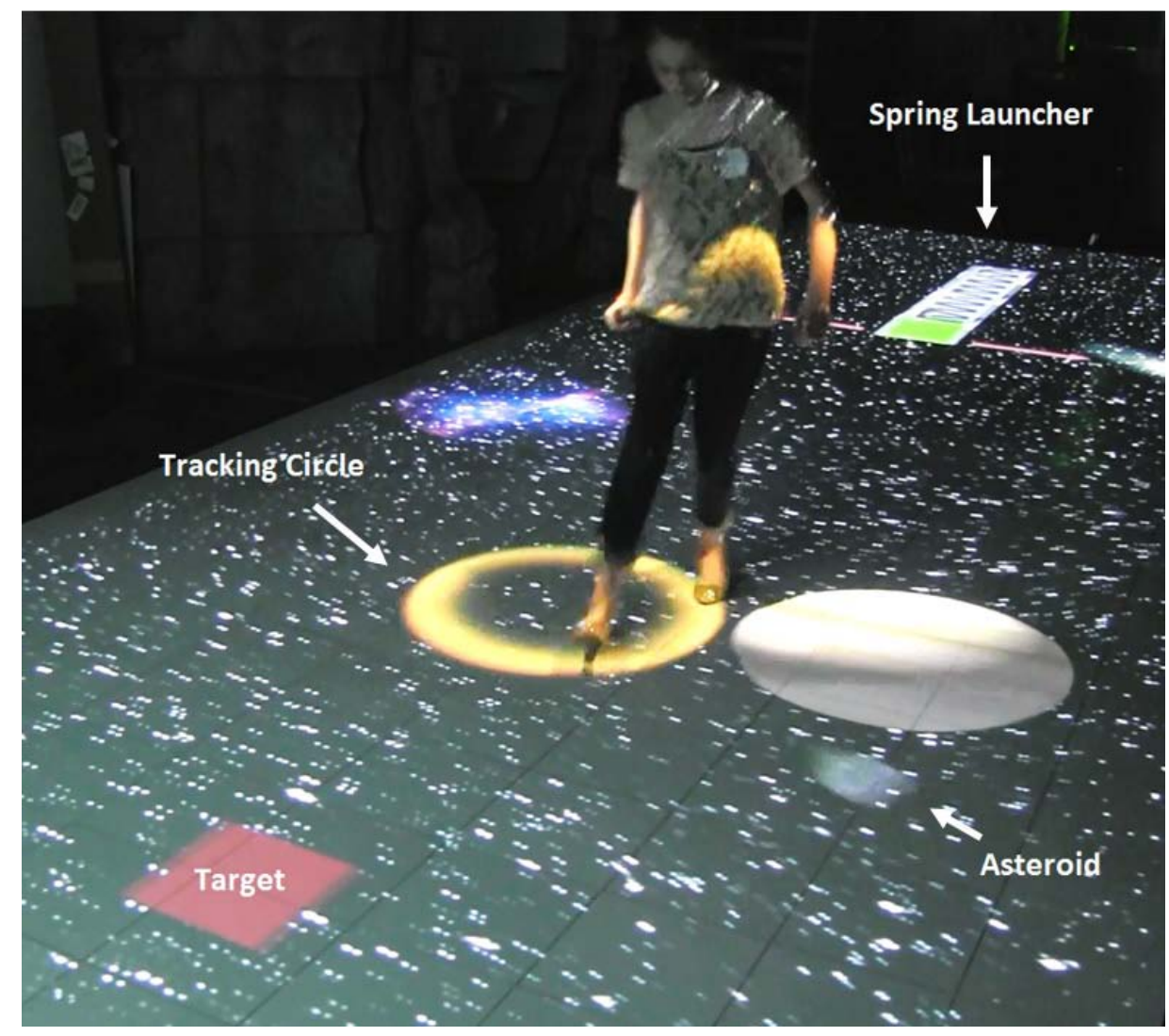

Figure 1. The MEteor simulation floor showing level 2. A participant has launched her asteroid and is predicting its path through the simulation field. The tracking circle is showing the participant's position, but the actual asteroid has sped up and curved around the planet.

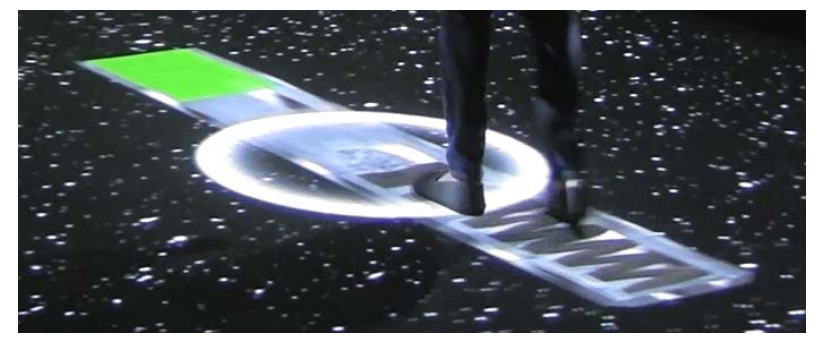

Figure 2. A participant loading their asteroid into the virtual spring launcher. 


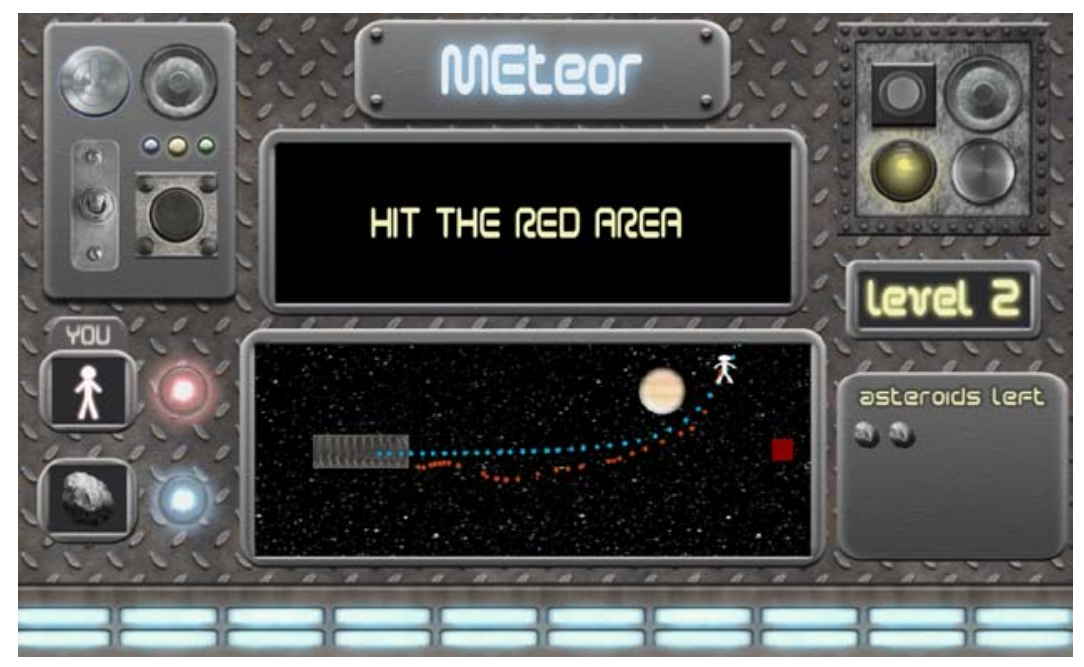

Figure 3. The MEteor wall display showing a graphical replay of the participant's previous launch.

The four simulation "levels" that participants worked through were designed to scaffold a learner's developing understanding of gravitational forces and how objects move in space. In level 1, participants are given the relatively simple task of hitting a target with the asteroid without any gravitational forces present. The target is a red square located at the opposite end of the simulation field as the spring launcher. One purpose of this level is to familiarize students with the basic mechanics of the launcher. However, in this level students also experience the notion that objects traveling in space will move with a constant velocity if no forces are present. In level 2 (Figure 1), the red square target remains in the same location but a large planet is added to the left side of the simulation field. To be successful at hitting the target, students need to take into account the gravitational forces exerted by the large planet (e.g., positioning the launcher away from the planet and allowing the asteroid to curve into the target). In level 3 (Figure 4), a smaller planet appears directly in front of the target, rather than off to the side of the planet as in level 2. This level can only be completed successfully by launching the asteroid to 
the side of the planet such that it makes a partial orbit and swings around into the target. The key difference between levels 2 and 3 is that in level 3, participants need to work with gravity and gain a sense of how objects might fall into orbit, as opposed to trying to directly counteract gravity. In the fourth and final level learners are prompted to "make the asteroid go completely around the planet." In this level, a mid-sized planet is positioned 5-6 feet from the spring launcher and participants are asked to find the launch parameters that effectively place the asteroid into a sustained orbit (e.g., launching tangentially to the planet's axis with sufficiently low velocity). The asteroid's behavior in level 4 exhibits the natural creation of orbits and permits learners to observe how they are maintained through gravitational acceleration. The experience is meant to allow learners to feel through their bodies how moons, asteroids, and other satellites maintain a stable path around a planet (the phenomenon of 'constantly falling but missing').

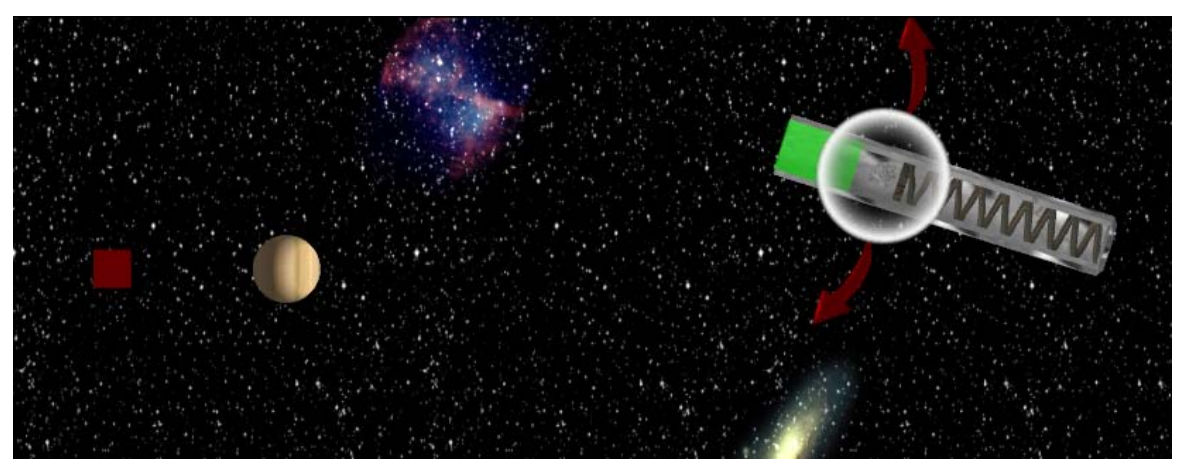

Figure 4. A simulation screenshot of level 3. The red target is placed behind a small planet. The user must use the gravity of the planet to curve the asteroid to the other side.

MEteor was designed purposefully to give students experiences in a world that they may find counterintuitive. The common misconception of an object absorbing a force that gradually dissipates (cf., Clement, 1982) is challenged in these levels when participants must coordinate 
their launches with a gravitational system and explore dynamic properties of orbits such as how an orbiting object will speed up and slow down depending on its distance from the planet. We observed in levels 1 and 4, for example, that students will initially give their asteroids more velocity than is required, presumably based on the belief that the velocity would otherwise "die out" before hitting the target or making it around the planet. We have written elsewhere about the strong potential for embodied and interactive systems like MEteor to diagnose and remedy misconceptions (Author, 2014). In this paper we look at more general effects of learning and engagement with embodied technologies compared to more traditional computer-based learning environments.

\section{Material and Methods}

\subsection{Participants}

This study was comprised of 113 seventh grade students (age 12 to 13; 47 male, 66 female) from three local middle schools who were transported to a university lab in groups of approximately 20 students over the course of several days. Students were randomly assigned to two groups: an experimental group that used the whole-body version of the simulation $(\mathrm{n}=58)$, and a control group that used a desktop version $(n=55)$. Because condition assignment occurred on multiple days with groups that sometimes had an odd number of participants the groups are not equal. All 113 participants completed all study procedures, but most of the measures used in this study were collected on a computer, and in a few cases a participant failed to enter a response for certain questions, either due to a computer glitch or an unwillingness to answer the question. In these fairly rare cases the participant was simply excluded from a particular statistical comparison. 


\subsection{Procedure}

The simulations used in the whole-body and desktop conditions differed in terms of how the simulation was controlled-i.e., with whole-body movement (walking and running) or with a computer mouse. The difference in how the simulation was controlled meant that the perspective the participants had on the simulation differed — sitting and viewing an image on a screen versus standing atop that image. Whole-body participants used the version of MEteor that was projected onto the floor and wall of a room described above, whereas desktop participants used a version displayed on a desktop computer (Figure 5). Other than which version of the simulation was used, all other study procedures were the same for both conditions. Before using the simulation, all participants were given a short survey that included science attitude and efficacy items. After using the simulation, participants were asked questions about forces and motion, planetary astronomy concepts, as well as their science attitudes and efficacy. Both the pre- and postsurveys were administered via a web-based questionnaire. Use of the MEteor simulation in both formats took approximately 20 minutes, and the full study session had a duration of approximately one hour.

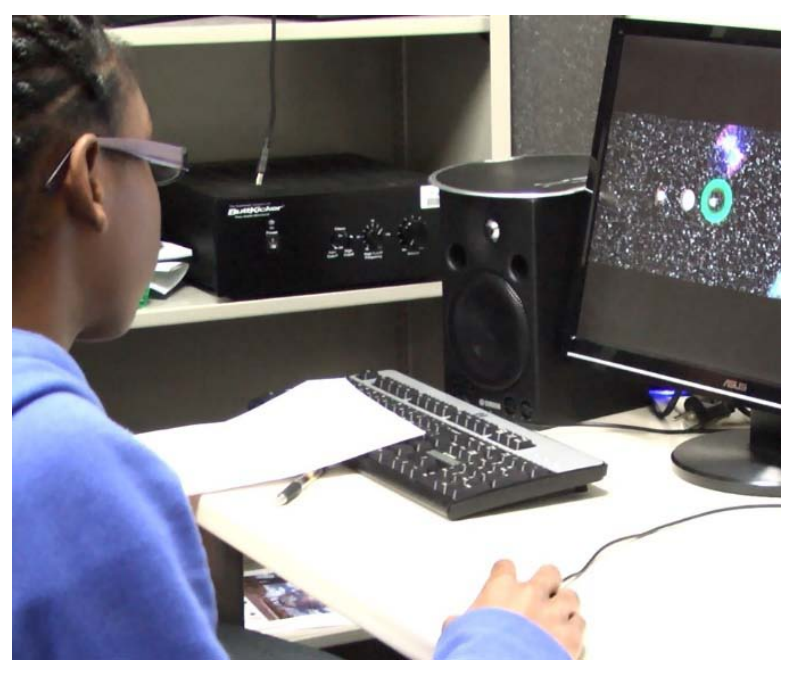

Figure 5. A control condition participant using the desktop version of MEteor. 


\subsection{Learning and Engagement Measures}

2.3.1 FCI questions. To assess the impact of using the simulation-either the wholebody or desktop version-we adapted a subset of 12 items from the Force Concept Inventory (FCI) (Hestenes, Wells \& Swackhammer, 1992). To avoid priming students to pay particular attention to these concepts during their use of the simulation, no FCI questions appeared on the pretest. The items were selected on the basis of the relevance of concepts of force and motion addressed within the simulation. One question, for example, asked students to reason about the forces acting on a ball that had been tossed up into the air. This question requires a participant to articulate the relationship between forces present in the environment and the motion of an object at various points in its trajectory. These items can reveal intuitive ideas and primitive ideas about physics that often arise from everyday experience, such as the expectation that constant force is required to keep an object in motion — an expectation consistent with the observation that objects typically stop moving when a force is taken away (due to the presence of friction). The MEteor simulation directly confronted these ideas by showing objects moving with constant velocity in the absence of forces, and increasing in velocity in the presence of a constant force (gravity), demonstrating the Newtonian principle that constant force implies constant acceleration. Administration of these FCI questions allowed us to observe any differences in participant reasoning about these notions in relation to their use of the whole-body or desktop version of the simulation. It should be noted that the FCI questions are designed for students at college level and therefore typically difficult for middle-school-aged students, and that we intentionally chose questions that would be challenging in order to get sufficient variability on participant responses.

2.3.2 Physics in space questions. Specific insights into gravity and orbital motion addressed in MEteor were probed using an additional set of 3 items (Appendix A) asking about 
concepts such as the effect of gravity on an object relative to its distance from a planet. Kavanagh \& Schneider (2006) report that many students believe that orbits are circular and that they are unrelated to gravity. They suggest that this notion is connected to the belief that objects in space are weightless and that therefore gravity has no effect on them. Students also have unclear ideas about the effect of gravity in relation to distance between objects, such as the belief that gravity may only have an effect if objects are very close, or that the effects are always the same independent of the distance, or even that the effect only exists in the case that there is an atmosphere. Again we administered these questions to determine whether there may be differences in understanding of these ideas based on how participants interacted with the simulation.

2.3.3 Attitude and efficacy questions. In addition to potential effects on physics knowledge, we were interested in whether the degree of embodied interaction had an impact on participants' feelings toward the simulation as well as ideas about their own abilities as they relate to science. To this end we gauged participant responses to the simple prompts "I enjoyed using the simulation game" and "I felt that the simulation game helped me to learn" on a 6-point Likert scale.

A further area that we examined was science self-efficacy. Student beliefs of self-efficacy have a strong influence on academic behavior and success (Bandura, Barbaranelli, Caprara, \& Pastorelli, 1996). Student interest in topics or themes of study have also been linked to improved motivation and learning (Linnenbrink \& Pintrich, 2003). Student emotion toward academic subjects can predict interest, motivation (both intrinsic and extrinsic), learning strategies, and even levels of academic achievement (Pekrun, Goetz, Titz, \& Perry, 2002). In order to examine potential short-term changes in feelings of self-efficacy as a result of using different versions of 
the MEteor simulation, participants were asked to respond to items in both the pre- and postsurveys (Appendix B) that were adapted from the Modified Attitudes Towards Science Inventory (MATSI) (Weinburgh \& Steele, 2000). These questions were drawn from the three subcategories of attitudes toward science: enjoyment of science, value of science in society, and self-concept in science. Items were similar but differed slightly from pre to post.

2.2.4 Presence and engagement questions. In order to understand how embodied interaction affects feelings of engagement and immersion, we asked a set of questions to probe the degree of cognitive and perceptual involvement participants felt in their experience with MEteor (Appendix C). These questions were modified from previous studies and instruments examining feelings of presence in simulations and digital media environments (e.g., Witmer \& Singer, 1998). Our interest was in understanding the extent to which participants using the two versions of the simulation perceived the virtual elements as being authentic objects in science, and the degree to which they were engaged with the actions and outcomes of the experience. Measures of reported presence are important to gain insight into how much, from a sensory and cognitive point of view, a participant is interacting with and in a virtual environment as if it were real.

\section{Results}

\subsection{Difference in Physics Understanding.}

Multiple measures were examined to study the differences between the whole-body interaction group and the desktop group. Thus multivariate analyses were performed to control for type 1 error. It was found that overall there was a significant difference between the two groups, Wilks' lambda $=.88, F(6,106)=2.46, p<.005$. Thus, follow-up tests were performed to further investigate the differences. 
3.1.1 FCI questions. In order to determine whether students differed in their general understanding of physics concepts across the whole-body and desktop conditions, we performed tests on participants' scores on the 12 FCI questions administered. There was a significant difference between the two groups, $F(1,112)=5.05, p=.027$, with students in the whole-body group $(M=3.67, S D=1.60)$ showing higher scores than those in the desktop group $(M=3.00$, $S D=1.58)$. Although the associated R-squared (.04) was not particularly large, this was likely limited by not having a larger sample size.

3.1.2 FCI questions +3 physics in space questions. The 3 space questions were added to the twelve FCI questions in order to obtain a more complete picture of MEteor's impact on student knowledge, inclusive of concepts specific to physics in space. As with the first analysis, it was found that students in the whole-body group $(M=4.84, S D=1.78)$ received significantly higher scores than those in the desktop group $(M=4.13, S D=1.74), F(1,112)=4.67, p=.033$.

\subsection{Perceptions of MEteor}

Perceptions of MEteor were analyzed separately with multivariate analyses because they were on different scales from other variables. More details regarding the scales can be found in Table 1.

3.2.1 "I enjoyed using the simulation game." In addition to the understanding of physics questions, we also looked for differences in students' self-reported enjoyment of the simulation game. The whole-body group reported significantly higher levels of enjoyment $(M=$ $5.26, S D=0.87)$ than the desktop group $(M=4.69, S D=1.15), F(1,107)=7.94, p=.006$.

3.2.2 "I felt that the simulation game helped me to learn." Students were also asked to self-report their perceptions of learning from the game. Significantly higher scores were found for the whole-body group $(M=5.00, S D=0.88)$ over the desktop group $(M=4.30, S D=1.11)$, 
$F(1,107)=14.85, p<.001$. Refer to Table 1 for a summary of all knowledge and engagement results described thus far.

Table 1

Summary of Comparisons of Learning and Engagement Questions Between Whole-Body (Experimental) and Desktop (Control) Versions of the Simulation

\begin{tabular}{|c|c|c|c|c|}
\hline & Desktop Group & $\begin{array}{c}\text { Whole-Body } \\
\text { Group }\end{array}$ & \multirow[b]{2}{*}{$F$} & \multirow{2}{*}{$\begin{array}{c}\text { Effect } \\
\text { Size } \\
R- \\
\text { Squared } \\
\end{array}$} \\
\hline & $M(S D)$ & $M(S D)$ & & \\
\hline 12 FCI Questions & $3.00(1.58)$ & $3.67(1.60)$ & $5.05^{*}$ & .04 \\
\hline $\begin{array}{l}12 \text { FCI Questions + } 3 \\
\text { Space Questions }\end{array}$ & $4.13(1.74)$ & $4.84(1.78)$ & $4.67 *$ & .04 \\
\hline Enjoyed the Simulation & $4.69(1.15)$ & $5.26(0.87)$ & $7.94 * *$ & .07 \\
\hline $\begin{array}{l}\text { Simulation Helped } \\
\text { Learning }\end{array}$ & $4.30(1.11)$ & $5.00(0.88)$ & $14.85^{* * *}$ & .12 \\
\hline
\end{tabular}

Note. The reported items have different scales. "12 FCI Questions" have a maximum possible score of 12. "12 FCI Questions + 3 Space Questions" have a maximum possible score of 15. "Enjoyed the Simulation" and "Simulation Helped Learning" has a Likert scale of $1-6$. $* p<.05 . * * p<.01 . * * * p<.001$.

\subsection{Science Efficacy Questions}

To analyze the responses to the pre and post science efficacy questions listed in Appendix $\mathrm{B}$, first an independent $t$ test was performed to determine if there was a difference in the perceptions of the two groups on the pretest. The results indicated that there was no difference between perceptions on the pretest science efficacy between the two groups, $t(111)=0.75, p=$ .455. Next, an ANCOVA was utilized to understand the change of student perceptions between the two groups (whole-body and desktop condition), in order to take into account the pretest and explain the posttest differences between the two groups. The results showed that the pretest scores significantly predicted the posttest scores, $F(1,110)=80.29, p<.001$. It also showed that 
there was a significant difference between the two groups, $F(1,110)=4.84, p=.030$, with the whole-body group $(M=4.67, S D=0.90)$ predicting significantly higher scores than the desktop group $(M=4.46, S D=0.98) \cdot \eta^{2}=.43$, which indicated that the effect size was large.

Table 2

Summary Comparisons of Science Efficacy Questions Between Whole-Body (Experimental) and Desktop (Control) Versions of the Simulation

\begin{tabular}{|c|c|c|c|c|}
\hline & Desktop Group & $\begin{array}{l}\text { Whole-Body } \\
\text { Group }\end{array}$ & & $\begin{array}{l}\text { Effect } \\
\text { Size } \\
2\end{array}$ \\
\hline & $M(S D)$ & $M(S D)$ & $F(1,110)$ & $\eta^{2}$ \\
\hline Science Efficacy & $4.46(0.98)$ & $4.67(0.90)$ & $4.84 *$ & .43 \\
\hline
\end{tabular}

$* p<.05$.

\subsection{Presence and Engagement Questions}

Ten presence and engagement items were administered that were grouped under four constructs: concentration, immersion, challenge, and autonomy/control (see Appendix C for specific items). Confirmatory factor analysis was performed to examine the groupings applied to the ten items, to investigate whether or not the items were measuring what we intended to measure. The results indicated that we had a very reliable structure, and the ten items designed were measuring the four constructs well: $\chi^{2}(29)=32.77, p=.29 ; \mathrm{CFI}=.99 ; \mathrm{GFI}=.94$; SRMSR $=.05 ;$ RMSEA $=.04$. All criteria suggest that the latent variables have very strong factor validity.

Next, we tested the four constructs, and compared them between the desktop group and the whole-body group. Results indicated a significant difference for concentration between the two groups, $F(1,112)=4.12, p=.045$, with the whole-body group $(M=4.92, S D=0.94)$ receiving higher scores than the desktop group $(M=4.52, S D=1.17)$. It was also indicated that there was a significant difference for immersion between the two groups, $F(1,112)=8.9, p=$ 
.004 , with the whole-body group $(M=4.45, S D=0.96)$ receiving higher scores than the desktop group $(M=3.91, S D=0.96)$. Similarly, the whole-body group $(M=4.72, S D=0.99)$ had significantly higher scores than the desktop group $(M=4.32, S D=1.09)$ on the challenge factor, $F(1,112)=4.33, p=.040$. However, no significant effects were found for the autonomy/control factor between the whole-body group $(M=4.81, S D=0.95)$ and the desktop group $(M=4.65$, $S D=0.98), F(1,112)=.73, p=.39$.

Table 3

Summary Comparisons of Presence and Engagement Questions Between Whole-Body (Experimental) and Desktop (Control) Versions of the Simulation

\begin{tabular}{|c|c|c|c|c|}
\hline & Desktop Group & $\begin{array}{c}\text { Whole-Body } \\
\text { Group }\end{array}$ & \multirow[b]{2}{*}{$F$} & \multirow{2}{*}{$\begin{array}{c}\text { Effect } \\
\text { Size } \\
R- \\
\text { Squared }\end{array}$} \\
\hline & $M(S D)$ & $M(S D)$ & & \\
\hline Concentration Questions & $4.52(1.17)$ & $4.92(0.94)$ & $4.12 *$ & .04 \\
\hline Immersion Questions & $3.91(0.96)$ & $4.45(0.96)$ & $8.9 * *$ & .07 \\
\hline Challenge Questions & $4.32(1.09)$ & $4.72(0.99)$ & $4.33 *$ & .04 \\
\hline $\begin{array}{l}\text { Autonomy/Control } \\
\text { Questions }\end{array}$ & $4.65(0.98)$ & $4.81(0.95)$ & .73 & .01 \\
\hline
\end{tabular}

Note. All of the questions have a Likert scale of $1-6$. $* p<.05 . * * p<.01$.

\section{Discussion}

All participants in the study used an interactive simulation game to learn about how objects move in space through a series of levels. Only in the whole-body condition, however, did the participants make their predictions and enact their understanding through gross body movement embedded within the simulation, entailing a first-person rather than-as in the desktop condition-a birds-eye perspective on scientific phenomena. The learner becomes an active partner in creating and experiencing science events that frequently challenge their expectations 
and counter their intuitions. Rather than relying on physical interaction alone, from within the MEteor simulation participants can merge their sensorimotor perceptions with augmented representations and digital scaffolds that make critical concepts salient. By employing dynamic imagery and eliciting analogies to how physical objects - including the body-behave in the physical world, participants are essentially enacting the reasoning processes of science experts (Clement, 1991), which may contribute to new learning. Results reported here demonstrate that learners in the embodied interaction condition are adopting more expert-like knowledge of science concepts as measured by a standard inventory. The FCI is the most commonly used battery to test for the effect of instruction on conceptual change. It is important to note that the questions probe for deep conceptual knowledge that affects a broad range of reasoning around force and motion, not only an understanding of the concepts addressed in MEteor. When specific questions about how objects move in space were added to the analysis, the effect favoring the whole-body group remained significant.

These results support the premise that embodied interaction with digital technologies can effectively anchor the rethinking and development of core concepts that are traditionally presented to learners through symbolic notation (cf., Author, 2013). Manipulating a computer mouse with the micro-movements of one's hand entails a much lower degree of embodiment (Johnson-Glenberg et al., 2014), and does not provide the same level of grounding as fully moving one's body within a simulation. This level of grounding is often hypothesized to be effective for learning and reasoning because concepts may emerge from concrete sensorimotor experiences that are developed into cognitive structures (e.g., Lakoff \& Johnson, 1980). Through direct comparison of two modes of interaction with the same simulation, our results show that 
'being' an object within a simulation environment can have powerful effects on learning relative to the more distal referencing inherent in traditional computer simulations.

Using one's body within the simulation naturally allows students to enact a set of movements with which they are familiar from everyday life (walking, running, etc.). While the novelty of this simulation may certainly have some effect on students' self-reported enjoyment and learning, we argue that it is the familiarity of such movements as well as the higher degree of physical involvement that decreases the distance between knowledge that learners perceive to be difficult to learn, leading to the higher overall gains on an assessment of participant attitudes towards science. While students at school are often required to identify mappings across different symbolic notations (e.g., formulae and diagrams), in the MEteor environment learners can relate more easily their experiences to a single symbolic representation that provides an isomorphic picture of the learners' bodily experience. For example, a quicker pace in walking or running, and deviations from the actual path of the asteroid, are reproduced symbolically, but with close resemblance to the actual movement and experience of the body. Enyedy et al. (2012) argue that such gradual symbolizations make more abstract and professional scientific representations more accessible than the representations commonly used in classrooms. This increase in familiarity and the explicit connections between experiences and representations could explain the significant difference between self-reported enjoyment and self-reported perception of learning in this study. Physical activities, it would seem, more effectively steer children's view of science as being about the real world, rather than an obscure practice involving highly abstract representations. Engagement and efficacy findings are also likely related to the result that participants in the whole-body condition reported higher levels of presence in 3 out of 4 of the associated factors. The control/autonomy factor did not show significant effects, possibly 
because even in the control condition the participant is unambiguously in control of the simulation while they manipulate the computer mouse. Overall the full-body experience led to a heightened sense of 'being there,' which again suggests a decrease in the distance between learner and learning content.

The practical significance of this study is that it suggests that there is value to finding ways to incorporate physical activity into technology-based learning interactions, both in terms of learning and affective engagement. In contributes to existing research showing the benefits of tangible and embodied interaction with educational technologies (e.g., Black et al., 2011; Chiu et al., 2015; Han \& Black, 2011), but also extends this work to suggest that there are particularly beneficial modes of physical interaction, particularly the embedding of one's body and perspective within an interactive simulation. These experiences can create powerful forms of feedback that are anchored on learner predictions and actions in real time. It also suggests that there may be additional features that could further enhance learning, such as giving physical feedback (e.g., devices that apply some directing force to the learner) in relation to their distance to the planet exerting the gravitational force.

This work also demonstrates how embodied simulations can create a palpable dissonance between learner ideas and the normative ideas of a domain such as planetary astronomy. This dissonance can be used both to make concepts explicit and to motivate learners to reconcile existing knowledge with more sophisticated understandings. It further shows the value of designing learning technologies around the experience of accomplishing a task (e.g., navigating a path) as opposed to simply completing an objective (e.g., hitting a target). Other learning and problem solving environments will focus on how learners reach a set target, de-emphasizing the role of sensorimotor experience in how they got there. This study should therefore be seen as 
demonstrating how learning experiences involving embodied interaction can be designed, and that measures and tests drawn from more traditional studies can be employed conjointly with new measures. Based on the positive results of this study, we recommend further exploration of how embodied interaction can support a variety of educational outcomes in other content areas, and how it may facilitate understanding of more abstract and crosscutting concepts.

A limitation of this study was that it did not examine long-term learning effects or the ability of this learning to transfer to new situations, though there is some emerging evidence that embodied learning has more resiliency than less-embodied instructional approaches (JohnsonGlenberg et al., 2014). A second limitation is that the intervention in this study was relatively short - participants spent approximately 20 minutes using either version of the simulation. While the differences between conditions on our various measures were significant in many cases, the effect sizes and overall impacts on the knowledge assessments, for example, were not massive. It is possible that the short duration of the experience was a reason for this, and it would be helpful to run future studies that investigate the effects of a more sustained intervention, such as using the body to engage in more topics or exploring the same topic from different perspectives. A third limitation is that the MEteor environment uses an embodied metaphor that is fairly literal in the sense that the motion of one's body represents the motion of an asteroid. We believe that there is the potential for embodied interaction to also improve reasoning using less literal and more abstract metaphors, such as body movement representing changes in scale or more complicated processes such as chemical reactions. New simulation designs and subsequent research efforts will be needed, however, to test this hypothesis. Finally, we are aware of the novelty and technological complexity of the simulation used in our study, and we understand that these kinds of environments will not be commonplace in classrooms and other typical learning 
environments in the very short term. However, mixed and augmented reality technologies are rapidly becoming cheaper and more accessible, making the potential for wider application and broader research with these kinds of interactions likely in the not-too-distant future.

\section{Conclusions}

Experimental evidence has been provided for both cognitive and motivational benefits of a simulation that allows a learner to become embedded within a dynamic system with complex components and relationships through embodied interaction. Compared to using the identical simulation through traditional mouse and keyboard controls, the group of participants who used their whole bodies to enact their predictions and engage with physics concepts showed higher learning and more positive attitudes toward the simulation experience and toward the learning environment. Our findings support the idea that new learning designs can be effectively grounded in real-time sensorimotor experiences. When combined with appropriate cuing mechanisms and representational supports, full-body interactive simulations hold significant promise for building student understanding of normative ideas in domains such as science. These interactive environments also afford the opportunity to experience science phenomena from new perspectives that change the affective and motivational disposition of the learner. Results of this research pave the way for further studies on the potential of full-body interactions and embodied metaphors in new domains, and how to design them for maximum educational impact.

\section{Acknowledgments}

[Removed for Blind Review] 


\section{References}

Abrahamson, D. (2014). Building educational activities for understanding: An elaboration on the embodied-design framework and its epistemic grounds. International Journal of ChildComputer Interaction, 2(1), 1-16.

Anastopoulou, S., Sharples, M., \& Baber, C. (2011). An evaluation of multimodal interactions with technology while learning science concepts. British Journal of Educational Technology, 42(2), 266-290.

Author. (2015).

Author. (2014).

Authors (2014).

Author. (2013).

Author. (2012).

Author. (2009).

Bandura, A., Barbaranelli, C., Caprara, G. V., \& Pastorelli, C. (1996). Multifaceted impact of self-efficacy beliefs on academic functioning. Child Development, 67(3), 1206-1222.

Barnett, M. (2005). Using virtual reality computer models to support student understanding of astronomical concepts. Journal of Computers in Mathematics and Science Teaching, 24(4), 333-356.

Barsalou, L. W. (1999). Perceptual symbol systems. Behavioral and Brain Sciences, 22, 577660.

Black, J. B., Segal, A., Vitale, J., \& Fadjo, C. (2011). Embodied cognition and learning environment design. In D. Jonassen \& S. Land (Eds.), Theoretical Foundations of Learning Environments (2nd ed., pp. 198-223). New York, NY: Routledge. 
Bujak, K. R., Radu, I., Catrambone, R., MacIntyre, B., Zheng, R., \& Golubski, G. (2013). A psychological perspective on augmented reality in the mathematics classroom. Computers \& Education, 68, 536-544.

Chang, C-W., Lee, J-H., Wang, C-Y., \& Chen, G-D. (2010). Improving the authentic learning experience by integrating robots into the mixed-reality environment. Computers \& Education, 55(4), 1572-1578.

Cheng, M. F., \& Brown, D. E. (2010). Conceptual resources in self-developed explanatory models: The importance of integrating conscious and intuitive knowledge. International Journal of Science Education, 32(17), 2367-2392.

Chiu, J. L., DeJaegher, C. J., \& Chao, J. (2015). The effects of augmented virtual science laboratories on middle school students' understanding of gas properties. Computers \& Education, 85, 59-73.

Clark, D., \& Jorde, D. (2004). Helping students revise disruptive experientially supported ideas about thermodynamics: Computer visualizations and tactile models. Journal of Research in Science Teaching, 41(1), 1-23.

Clement, J. (1982). Students' Preconceptions in Introductory Mechanics, American Journal of Physics, 50(1), 66-71.

Clement, J. (1991). Nonformal reasoning in experts and in science students: The use of analogies, extreme cases, and physical intuition. In Voss, J. F., Perkins, D. N., \& Segal, J. W. (Eds.). Informal reasoning and education (pp. 345-362). Routledge.

Cohen, J. (1988). Statistical power analysis for the behavioral sciences (2nd ed.). New York: Academic. 
Colella, V. (2000). Participatory simulations: Building collaborative understanding through immersive dynamic modeling. The Journal of the Learning Sciences, 9(4), 471-500.

Dalgarno, B., \& Lee, M. J. (2010). What are the learning affordances of 3-D virtual environments? British Journal of Educational Technology, 41(1), 10-32.

D’Angelo, C., Rutstein, D., Harris, C., Bernard, R., Borokhovski, E., \& Haertel, G. (2014). Simulations for STEM learning: Systematic review and meta-analysis. Menlo Park: SRI International.

Dede, C. (2009). Immersive interfaces for engagement and learning. Science 323(5910), 66-69.

De Freitas, S., Rebolledo-Mendez, G., Liarokapis, F., Magoulas, G., \& Poulovassilis, A. (2010). Learning as immersive experiences: Using the four-dimensional framework for designing and evaluating immersive learning experiences in a virtual world. British Journal of Educational Technology, 41(1), 69-85.

de Jong, T., \& van Joolingen, W.R. (1998). Scientific discovery learning with computer simulations of conceptual domains. Review of Educational Research, 68, 179-201.

Dunleavy, M., Dede, C., \& Mitchell, R. (2009). Affordances and limitations of immersive participatory augmented reality simulations for teaching and learning. Journal of Science Education and Technology, 18(1), 7-22.

Enyedy, N., Danish, J. A., Delacruz, G., \& Kumar, M. (2012). Learning physics through play in an augmented reality environment. International Journal of Computer-Supported Collaborative Learning, 7(3), 347-378.

Falloon, G. (2010). Using avatars and virtual environments in learning: What do they have to offer?. British Journal of Educational Technology, 41(1), 108-122. 
Gallese, V., \& Lakoff, G. (2005). The brain's concepts: The role of the sensory-motor system in conceptual knowledge. Cognitive neuropsychology, 22(3-4), 455-479.

Gelbart, H., Brill, G., \& Yarden, A. (2009). The impact of a web-based research simulation in bioinformatics on students' understanding of genetics. Research in Science Education, $39(5), 725-751$.

Glenberg, A. (2010). Embodiment as a unifying perspective for psychology. Wiley Interdisciplinary Reviews: Cognitive Science, 1(4), 586-596.

Grant, E. R., \& Spivey, M. J. (2003). Eye movements and problem solving: Guiding attention guides thought. Psychological Science, 14, 462-466.

Goldin-Meadow, S., Cook, S. W., \& Mitchell, Z. A. (2009). Gesturing gives children new ideas about math. Psychological Science, 20(3), 267-272.

Han, I., \& Black, J. B. (2011). Incorporating haptic feedback in simulation for learning physics. Computers \& Education, 57(4), 2281-2290.

Hestenes, D., Wells, M., \& Swackhamer, G. (1992). Force concept inventory. The Physics Teacher, 30(3), 141-158.

Inhelder, B. \& Piaget, J. (1958). The growth of logical thinking from childhood to adolescence; an essay on the construction of formal operational structures. New York: Basic Books.

Jacob, R. J. K., Audrey, G., Hirshfield, L. M., Horn, C. A., Shaer, O., Solovey, E. T., \& Zigelbaum, J. (2008). Reality-based interaction: a framework for post-WIMP interfaces. Paper presented at the CHI Conference on Human Factors in Computing Systems.

Johnson, M. 1987. The body in the mind: The bodily basis of meaning, imagination, and reason. Chicago: University of Chicago Press. 
Johnson-Glenberg, M. C., Birchfield, D. A., Tolentino, L., \& Koziupa, T. (2014). Collaborative embodied learning in mixed reality motion-capture environments: Two science studies. Journal of Educational Psychology, 106(1), 86.

Jones, M. G., Minogue, J., Tretter, T. R., Negishi, A., \& Taylor, R. (2006). Haptic augmentation of science instruction: Does touch matter? Science Education, 90(1), 111-123.

Kafai, Y. B. (2006) Constructionism. In K. Sawyer (Ed.), Cambridge Handbook of the Learning Sciences (pp. 35-46). New York: Cambridge University Press.

Kavanagh, C., \& Sneider, C. (2006). Learning about gravity II. Trajectories and orbits: A guide for teachers and curriculum developers. Astronomy Education Review, 5(2), 53-102.

Lakoff, G., \& Johnson, M. (1980). Metaphors we live by. Chicago: University of Chicago Press

Linnenbrink, E. A., \& Pintrich, P. R. (2003). The role of self-efficacy beliefs in student engagement and learning in the classroom. Reading \& Writing Quarterly, 19(2), 119-137.

Luo, Z., Luo, W., Wickens, C. D., \& Chen, I. M. (2010). Spatial learning in a virtual multilevel building: Evaluating three exocentric view aids. International Journal of HumanComputer Studies, 68(10), 746-759.

Milgram, P., \& Kishino, A. F. (1994). Taxonomy of mixed reality visual displays. IEICE Trans. Information and Systems, E77-D(12), 1321-1329.

Monaghan, J.M., \& Clement, J. (1999). Use of a computer simulation to develop mental simulations for understanding relative motion concepts. International Journal of Science Education, 21(9), 921-944.

National Research Council. (2011). Learning Science through Computer Games and Simulations. Committee on Science Learning: Computer Games, Simulations, and Education, Margaret A. Honey and Margaret L. Hilton, Eds. Board on Science Education, 
Division of Behavioral and Social Sciences and Education. Washington, DC: The National Academies Press.

Nemirovsky, R., \& Ferrara, F. (2009). Mathematical imagination and embodied cognition. Educational Studies in Mathematics, 70(2), 159-174.

Niebert, K., Marsch, S., \& Treagust, D. F. (2012). Understanding needs embodiment: A theoryguided reanalysis of the role of metaphors and analogies in understanding science. Science Education, 96(5), 849-877.

Pekrun, R., Goetz, T., Titz, W., \& Perry, R. P. (2002). Academic emotions in students' selfregulated learning and achievement: A program of qualitative and quantitative research. Educational Psychologist, 37(2), 91-105.

Plummer, J. D. (2009). Early elementary students' development of astronomy concepts in the planetarium. Journal of Research in Science Teaching, 46(2), 192-209.

Resnick, M. (2006). Computer as paintbrush: Technology, play, and the creative society. In D. Singer, R. Golikoff, \& K. Hirsh-Pasek (Eds.), Play=learning: How play motivates and enhances children's cognitive and social-emotional growth. New York, NY: Oxford University Press.

Richards, T. (2012). Using kinesthetic activities to teach Ptolemaic and Copernican tetrograde motion. Science \& Education, 21(6), 899-910.

Richards, J., Barowy, W., \& Levin, D. (1992). Computer simulations in the science classroom. Journal of Science Education and Technology, 1(1), 67-79.

Rutten, N., van Joolingen, W. R., \& van der Veen, J. T. (2012). The learning effects of computer simulations in science education. Computers \& Education, 58(1), 136-153. 
Segal, A. (2011). Do gestural interfaces promote thinking? Embodied interaction: Congruent gestures and direct touch promote performance in math (Doctoral dissertation, Columbia University).

Smetana, L. K., \& Bell, R. L. (2012). Computer simulations to support science instruction and learning: A critical review of the literature. International Journal of Science Education, 34(9), 1337-1370.

Solomon, J., Bevan, R., Frost, A., Reynolds, H., Summers, M., \& Zimmerman, C. (1991). Can pupils learn through their own movements? A study of the use of a motion sensor interface. Physics Education, 26(6), 345.Stieff, M., \& Wilensky, U. (2003). Connected Chemistry-Incorporating interactive simulations into the chemistry classroom. Journal of Science Education and Technology, 12(3), 285-302.

Swaak, J., \& de Jong, T. (2001). Discovery simulations and the assessment of intuitive knowledge. Journal of Computer Assisted Learning, 17, 284-294.

van der Meij, J., \& de Jong, T. (2006). Learning with multiple representations: Supporting students' learning with multiple representations in a dynamic simulation-based learning environment. Learning \& Instruction, 16, 199-212.

Vitale, J. M., Swart, M. I., \& Black, J. B. (2014). Integrating intuitive and novel grounded concepts in a dynamic geometry learning environment. Computers \& Education, 72, 231248.

Weinburgh, M. H. \& Steele, D. (2000). The modified attitudes toward science inventory: Developing an instrument to be used with fifth grade urban students. Journal of Women and Minorities in Science and Engineering, 6(1). 
Wilson, M. (2002). Six views of embodied cognition. Psychonomic Bulletin \& Review, 9(4), 625-636.

Windschitl, M., \& Andre, T. (1998). Using computer simulations to enhance conceptual change: The roles of constructivist instruction and student epistemological beliefs. Journal of Research in Science Teaching, 35, 145-160.

Winn, W. (2003). Learning in artificial environments: Embodiment, embeddedness and dynamic adaptation. Technology, Instruction, Cognition and Learning, 1(1), 87-114.

Winn, W., Stahr, F., Sarason, C., Fruland, R., Oppenheimer, P., \& Lee, Y.-L. (2006). Learning oceanography from a computer simulation compared with direct experience at sea. Journal of Research in Science Teaching, 43(1), 25-42.

Witmer, B. G., \& Singer, M. J. (1998). Measuring presence in virtual environments: A presence questionnaire. Presence: Teleoperators and virtual environments, 7(3), 225-240.

Wu, H. K., Lee, S. W. Y., Chang, H. Y., \& Liang, J. C. (2013). Current status, opportunities and challenges of augmented reality in education. Computers \& Education, 62, 41-49. 


\section{Appendix A}

\section{Physics in Space Questions}

1. In which picture would the planet pull on the asteroid the strongest if the planets have the same density and the asteroids are the same distance from each planet's center?
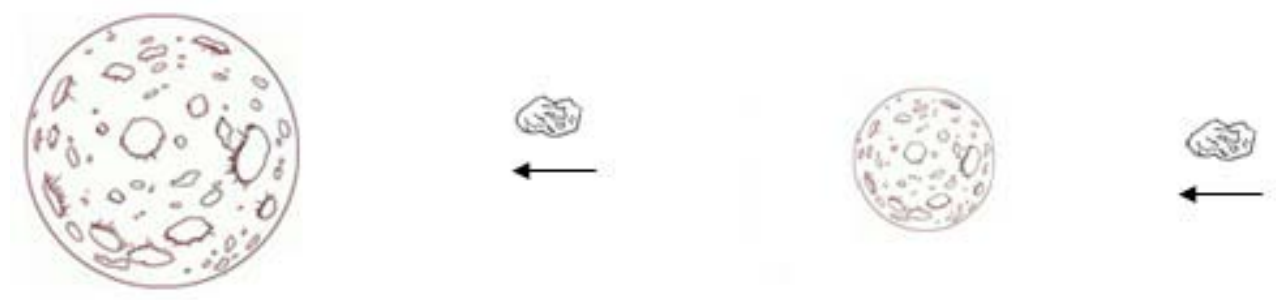

A

B

a. Planet A would pull on the asteroid the strongest.

b. Planet B would pull on the asteroid the strongest.

c. The planets would pull on the asteroid equally.

2. Which statement below most accurately explains the planet's speed in this picture?

A

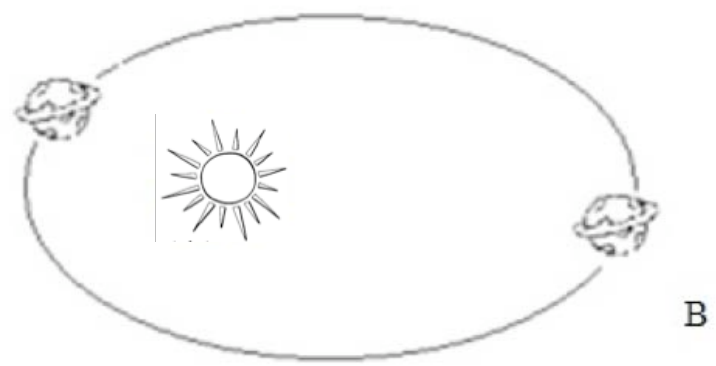

a. The planet is moving the same speed in both positions.

b. When the planet is in position A, it is moving faster than in position B.

c. When the planet is in position $\mathrm{B}$, it is moving faster than in position $\mathrm{A}$.

3. Why do artificial satellites stay in orbit?

a. They have powerful engines that push them away from the earth, to overcome the force of gravity.

b. A centrifugal force (a force that pulls them away from the center) is acting on them and overcoming the force of gravity.

c. The force of gravity constantly speeds up the satellites, which allows them to overcome earth's gravity.

d. They are at such a high altitude that they are not affected by gravity. 
e. The force of gravity of the earth is balanced out by the force of gravity from the moon.

\section{Appendix B}

\section{Science Efficacy Questions}

All item responses given on a 6-point Likert scale from strongly disagree to strongly agree (scales reversed in data analysis where appropriate).

3 pre-survey questions:

1. I enjoy talking to other people about science.

2. It is likely that science will NOT be part of my job someday.

3. I usually understand what we are talking about in science class.

3 post-survey questions:

1. I like science.

2. It is likely that doing science will be part of my job someday.

3. No matter how hard I try, I CANNOT understand science.

\section{Appendix C}

\section{Presence and Engagement Questions}

All item responses given on a 6-point Likert scale from strongly disagree to strongly agree.

Immersion/presence questions

1. My seeing and hearing senses were used fully in this simulation game

2. I lost track of events happening in the real world while I used this simulation.

3. I felt like I was really there.

4. I am interested in how well I did compared to others who played this game.

\section{Concentration}

5. It was easy to concentrate on the simulation.

6. I felt the simulation held my attention.

\section{Challenge}

7. The simulation had features that helped me overcome challenges.

8. I felt like I became more skilled in the simulation as I went.

\section{Autonomy and control}

9. I felt like I could control the things that happened in the simulation.

10. I understood my overall goals in the simulation. 